\title{
Students, concept maps and the issue of transfer
}

\author{
James E Herring \\ Lecturer in Teacher Librarianship \\ Charles Sturt University \\ Australia
}

This paper focuses on the use of concept maps by year 7 students in three rural schools in New South Wales, Australia. The study examined the views of students, teachers and teacher librarians on the use of concept maps and on the extent to which students would transfer concept mapping skills across time and across subjects. Grounded theory was used as the method for the study. Data was gathered via student diaries, questionnaires and interviews, and teacher and teacher librarian interviews. Data was analysed and interpreted using grounded theory techniques. Findings indicated that transfer was a complex issue for students and school staff.

Year 7 students; concept mapping; transfer of information literacy skills

\section{Introduction}

The context of this paper is a wider study by the author of the use of information literacy skills by year $7\left(1^{\text {st }}\right.$ year high/secondary school) students in three rural Australian schools. The paper also draws on previous research conducted by the author of year 7 and 8 students' use of concept maps in UK secondary schools. While the wider study examined students' views on and use of a range of information literacy skills (e.g. students' definition of purpose, question formulation and information retrieval), this paper focuses on students use of concept maps, which are also referred to as mind maps.

\section{Research questions}

The aims of the study were to examine the views of year seven students, teachers and teacher librarians on concept mapping, and to examine the extent to which year students were likely to transfer concept mapping skills across subjects and across time. The research questions were:

- How did students, teachers and teacher librarians view concept mapping as an information literacy skill?

- To what extent did students view concept mapping as a useful skill in relation to completing an assignment? 
- What were the views of students, teachers and teacher librarians on the transfer of concept mapping skills?

- To what extent did students transfer concept mapping skills across subjects and across time?

\section{Literature Review}

Information literacy has been one of the most widely discussed topics in the literature of teacher librarianship. While much of this literature is related to practice, there is a growing body of research related to information literacy with key authors including Kuhlthau (2004), Todd (2007), Farmer (2005), Barranoik (2004), Herring (2006), Wolf (2007) and Woolls and Loertscher (2002). Loertscher (2008) notes that despite the wide range of research and publications, a number of issues relating to information literacy remain unresolved. While some of the research into information literacy has included concept maps, few studies have focused on this topic in any depth. An examination of student views on concept maps were part of research by Herring, Tarter and Naylor (2002), Herring (2006), Herring and Hurst (2006) and Herring and Tarter (2007). These studies provided empirical evidence that students in both primary and secondary schools viewed concept mapping in a favourable light and saw a number of benefits in using concept maps. These benefits included improved question formulation, keyword generation and information retrieval. Students also used concept maps to identify prior knowledge and to identify gaps in existing knowledge. Concept maps could also aid students in evaluating the relevance of information retrieved and could be used as the basis for students to write up their assignments. The issue of students transferring concept mapping skills was examined only in the Herring and Hurst (2006) study.

Gordon (2000) found that, for some students, the use of concept maps improved the quality of searching and made students more likely to take a more metacognitive approach to information retrieval. In the field of education, Kinchin and Hay (2000) also cited improvements in metacognition and Cain (2004) examined primary school students' use of concept maps in relation to improving student literacy and confidence. None of these studies focused on whether students transferred information literacy skills such as concept mapping.

While there is much implied attention given to the concept of transfer in relation to information literacy, there is little coverage of this issue in the school related literature. In the wider education field, the transfer issue has been debated for over one hundred years. The focus of most educational literature on transfer is on the transfer of learning, and in particular, the transfer of learning content i.e. do students transfer knowledge from one subject to another or from one year to another? Whilst there is some focus on skills transfer in schools (Haskell 2001), this research has related to the transfer of skills in subject such as mathematics and modern languages. There does not appear to have been any previous studies of information literacy skills transfer in schools. Detterman (1993), Haskell (2001), Royer et al (2005) and Hakel and Halpern (2005) discuss definitions, theories and types of transfer in educational settings.

\section{Methodology}

A constructivist grounded theory approach was taken to the study. Grounded theory has progressed from the early work of Glaser and Strauss (1967) to Strauss and Corbin (1998) and constructivist grounded theory has been most influenced by Charmaz (2006). The 
key elements of constructivist grounded theory are that the researcher is viewed as an interpreter of the observed world and that data, such as student interviews, is viewed as construction of reality by participants in the study. The researcher examines what emerges from the data and does not approach the study with a preconceived hypothesis. Grounded theorists seek to explain studied phenomena but do not seek to generalise from their findings.

Within this constructivist grounded theory approach, the techniques used to gather data were student diaries (Harada 2002), student questionnaires (Patton 2002), student interviews and interviews with teachers and teacher librarians (Charmaz 2006). Grounded theory techniques were used to analyse and interpret the data and these techniques included initial and focused coding, category formulation, constant comparison and theoretical sampling. (Charmaz 2006). This study is part of a larger study of information literacy skills transfer and in the larger study, a grounded theory was developed.

\section{Findings}

The findings of the study present a complex picture of students', teachers' and teacher librarians' views on the value of concept maps, the use of concept maps and the extent to which students might be likely to transfer the use of concept maps across time and curricular subjects. Most students in the study had little experience of concept maps in primary school but the data showed that almost all students valued the use of concept maps. While some students could see extensive value in concept maps e.g. identifying future use of a map in relation to keyword and question formulation, information retrieval, seeking relevant information within sources and structuring an assignment, other students saw more limited value e.g. only in relation to information retrieval. A minority of students saw little value as they lacked understanding of the value of a concept map. Students used written concept maps when encouraged to do so by teachers and teacher librarians, who both saw extensive value in concept maps. When given the choice of using a written concept map, many students stated that they preferred to use a mental, rather than a written concept map, while other students did not use a concept map at all. Thus the issue of transfer is a complex one in the context of this study. There was some clear evidence of transfer, in that some students applied what they had learned about concept mapping in a previous term to a new subject assignment. On the other hand, many other students did not transfer what they had learned and the evidence showed that this was either because they did not understand the concept of transfer ( a small minority) or that they lacked motivation to transfer or that they expected the teacher and/or teacher librarian to tell them to use a concept map. It was clear from the study that there was no culture of transfer in these schools and that this made it unlikely that students, apart from a well motivated minority, would transfer skills.

\section{Discussion: Implications for teacher librarians}

While grounded theory studies do not seek to generalise the findings of individual studies, there are some potential implications for teacher librarians from this study. The study found that, while teachers and teacher librarians encouraged students to use concept maps when planning assignments, there was little evidence that those teachers and teacher librarians had much knowledge about the students' views on the use of concept maps and in particular, the preference for mental maps by many students. Teacher librarians may wish to consider how much they know about their own students' use of concept maps. One way to increase this knowledge is to discuss concept mapping as a skill and a technique with the students themselves. The study also found that teachers and teacher librarians had a number of assumptions about students' understanding of concept mapping, but that these assumptions 
did not always match the students' actual capabilities. The most common assumption was that students would, if introduced to concept mapping, fully understand the potential use of the concept map. In practice, many students had a limited view of how a concept map could be used e.g. mainly for information retrieval. Teacher librarians may wish to explore students' understanding of the use of concept maps, as well as the development of concept maps. If teacher librarians can explain how a concept map can be used throughout the assignment process, students are likely to make better use of their concept maps.

In this study, both teachers and teacher librarians appeared to have a limited understanding of the complexities surrounding the transfer of information literacy skills, including concept mapping. Transfer was discussed only anecdotally in the schools and it appeared that lip-service was paid to developing transfer. Teacher librarians could view this lack of emphasis on transfer in schools as an opportunity to learn more about skills transfer and to play a role in developing a culture of transfer in their schools.

\section{Conclusion}

This study has provided empirical evidence from three schools about year seven students and concept mapping. Future research could investigate students in the upper levels of secondary school and focus on the extent to which students continue to use concept mapping and also how students develop their own individual information literacy model.

Note: A fuller version of this paper will be sent to School Libraries Worldwide for consideration as a refereed publication. The author's university no longer recognises conference proceedings as refereed publications.

\section{References}

Barranoik, L., (2004). Students and their research: architects of meaning. SCAN, Vol.23, No. 2, 33-37.

Cain, M., (2004). Using mind-maps to raise standards in literacy, improve confidence and encourage positive attitudes towards learning. Viewed 22 January 2009,

< http://www.standards.dfes.gov.uk/ntrp/lib/pdf/Cain.pdf>

Charmaz. K., (2006) Constructing grounded theory: a practical guide through qualitative analysis. Sage, London.

Detterman, D., (1993). The case for the prosecution: transfer as an epiphenomenon In Detterman, D and Sternberg, R 1993, 'Transfer on trial: intelligence, cognition and instruction'. Ablex Publishing, Norwood, NJ.

Farmer, L., (2005). Social-emotional behavior and information literacy In S. Lee, P. Warning, D. Singh, E. Howe, L. Farmer and S. Hughes (Eds.) IASL Reports 2005: Information leadership in a culture of change. International Association of School Librarianship, Erie, PA:

Gordon, C., (2000) The effects of concept mapping on the searching behavior of tenth-grade students. School Library Media Research, vol. 2, article 6, viewed 13 May 2009, <http://www.ala.org/ala/aasl/aaslpubsandjournals/slmrb/slmrcontents/volume32000/mapping.htm>.

Hakel, M. and Halpern, D., (2005). How far can transfer go? In Mestre, J ed. 2005, Transfer of learning from a modern multidisciplinary perspective. Information Age Publishing, Greenwich, CT.

Harada, V., (2002) 'Personalising the information search process: a case study of journal writing with elementary-age students', School library Media Research, vol. 5, article 1, viewed 13 May 2009,,

<http://www.ala.org/ala/aasl/aaslpubsandjournals/slmrb/slmrcontents/volume52002/slmrvolume52002.htm>.

Haskell, R., (2001). Transfer of learning: cognition, instruction and reasoning. Academic Press, San Diego.

Herring, J., (2006). A critical investigation of students' and teachers' views of the use of information literacy skills in school assignments. School Library Media Research, vol. 9. Viewed 123 May 2009,

<http://www.ala.org/ala/aasl/aaslpubsandjournals/slmrb/slmrcontents/volume9/informationliteracy.cfm>

Herring, J. and Hurst, J., (2006). An investigation into the extent to which Year 6 students transfer information literacy across subjects In McGregor, J and Hay, L eds. Research in Teacher Librarianship: 
Proceedings of the Centre for Studies in Teacher Librarianship Research Conference, Australian National University, Canberra, 9-10 April 2005. Viewed 13 May 2009 $<$ http://www.csu.edu.au/faculty/educat/sis/CIS/epubs/CSTLpapers.htm>

Herring, J. and Tarter, A-M., (2007). Progress in developing information literacy in a secondary school using the PLUS model. School Libraries in View, Vol. 23, 3-7.

Herring, J., Tarter, A-M. and Naylor, S., An evaluation of the PLUS model to develop pupils' information skills in a secondary school. School Libraries Worldwide Vol.8, No.1, 1-24.

Kinchin, I. and Hay, D., (2000) How a qualitative approach to concept map analysis can be used to aid learning by illustrating patterns of conceptual development. Educational Research, Vol.42, No.1, 43-57.

Kuhlthau, C., (2004). Seeking meaning: a process approach to library and information services. $2^{\text {nd }}$ ed., Libraries Unlimited, Westport CT.

Loertscher, D., (2008) Information literacy: 20 years later. Teacher Librarian, Vol. 35 Issue 5, 42-43.

Patton, M., (2002) Qualitative research and evaluation methods. $3^{\text {rd }}$ ed., Sage Publications, thousand Oaks, CA.

Royer, J. Mestre, J. and Dufresne, R., (2005). Introduction: framing the transfer problem In Mestre, J ed. 2005, Transfer of learning from a modern multidisciplinary perspective. Information Age Publishing, Greenwich, CT. Todd, R., (2007). Guided inquiry supporting information literacy', Scan, vol. 26, no.2, 28-29.

Wolf, S., (2007) Information literacy and self-regulation: A convergence of disciplines. School Library Media Research, vol. 10, viewed 13 May 2009,

$<$ http://www.ala.org/ala/aasl/aaslpubsandjournals/slmrb/slmrcontents/volume10/wolf_informationliteracy.cfm>

Woolls, B. \& Loertscher, D., (2002). Information literacy: A review of the research: A guide for practitioners and researchers. 2nd ed. Hi Willow Research and Publishing, San José, CA.

\section{Biographical note}

James E Herring is a lecturer in teacher librarianship at Charles Sturt University, Australia. He was formerly head of the Department of Information Management at Queen Margaret University, Scotland. James is the author of nine books on teacher librarianship, information literacy and ICT in schools and of many research and professional articles.

\section{Statement of Originality}

This statement certifies that the paper above is based upon original research undertaken by the author and that the paper was conceived and written by the author(s) alone and has not been published elsewhere. All information and ideas from others is referenced. 